CARDIOVASCULAR MEDICINE

\title{
Growth of girls who later develop coronary heart disease
}

\author{
T Forsén, C Osmond, J G Eriksson, D J P Barker
}

Heart 2004;90:20-24

\begin{abstract}
Objective: To determine the path of growth of girls who later develop coronary heart disease.
Design: Follow up study of girls whose body size at birth, during infancy, and childhood up to age 12 years was recorded.

Setting: Helsinki, Finland.

Participants: 4130 girls who were born between 1934 and 1944, attended child welfare clinics in Helsinki, and were still resident in Finland in 1971.

Main outcome measure: Hospital admission or death from coronary heart disease.

Results: In comparison with boys in the same cohort who later developed coronary heart disease the 87 girls were short at birth, rather than thin, had compensatory growth in height during infancy, became thin, and thereafter had a rapid increase in weight and body mass index. In a combined analysis the hazard ratios for coronary heart disease were 1.17 (95\% confidence interval (CI) 1.03 to $1.32, p=0.02$ ) for each $1 \mathrm{~cm}$ decrease in length at birth, $1.52(95 \% \mathrm{Cl} 1.23$ to $1.89, \mathrm{p}<0.001)$ for each standard deviation score increase in body mass index after age 3 years, and $1.63(95 \% \mathrm{Cl} 1.09$ to $2.42, \mathrm{p}=0.02)$ for each decrease in level of education.

Conclusions: Though broadly similar, the paths of growth associated with the later development of coronary heart disease differ in girls and boys. This may be because girls are less vulnerable to undernutrition in utero and are better able to sustain postnatal growth in an adverse environment.
\end{abstract}

See end of article for authors' affiliations

......................

Correspondence to: Professor D J P Barker, Southampton General Hospital, Tremona Road, Southampton SO16 6YD, UK; dipb@mrc.soton.ac.uk

Accepted 30 April 2003
$\mathrm{T}$ he growth of children who later develop coronary heart disease differs from that of other children. Studies in Europe, the USA, and India have shown that these children tend to have low birth weight as a result of slow intrauterine growth. ${ }^{1-7}$ The association between low birth weight and coronary heart disease is thought to reflect persistence of changes in morphology and physiology that accompany slow fetal growth. The "fetal origins" hypothesis proposes that coronary heart disease originates through plasticity during development whereby undernutrition, hypoxia, or stress in utero initiate pathological changes that ultimately lead to clinical disease. ${ }^{89}$ The hypothesis is supported by experimental observations in animals, which show that manipulation of the diet of pregnant animals leads to persisting changes in the offspring, which include raised blood pressure and altered liver function. ${ }^{1011}$

We have previously reported on a cohort of girls born in Helsinki during 1924-33, ${ }^{4}$ whose growth during school years was recorded. Having been born with below average body size, the girls who later developed coronary heart disease were around the average for height and weight at age 15. At some point after birth they had therefore had rapid, compensatory growth, ${ }^{9}$ and it was the combination of slow intrauterine growth, followed by rapid compensatory growth that led to disease. We examined the growth of boys in a younger cohort of 8760 children who were born in Helsinki during 1934-44 and for whom there were sequential growth data from birth onwards. The boys who later developed coronary heart disease tended to be thin at birth and to have low weight gain in infancy but to have rapid compensatory weight gain after the age of 1 year. ${ }^{5}$ We now report on findings among girls.

\section{METHODS}

We studied girls who were born at Helsinki University Central Hospital during 1934-44 and who attended child welfare clinics in the city of Helsinki and were still resident in Finland in 1971. Details of the birth and child welfare clinic records have been described. ${ }^{45}$ The clinic records include serial measurements of height and weight.

We identified 5486 women who had birth and child welfare records. Of these, 4130 (75\%) were alive and living in Finland in 1971, when a unique identification number was allocated to each member of the Finnish population. Of these women $3136(76 \%)$ went to school in Helsinki and had school health records. Details of school health records have been described. ${ }^{12}$ They include measurements of height and weight recorded at periodic medical examinations from age 6 years onwards. Each girl had an average (SD) of 18 (10) measurements of height and weight between birth and 12 years of age.

Using the identification number, we identified all hospital discharges and deaths among the women during 1971 to 1998. All hospital discharges in Finland are recorded in the national hospital discharge register. All deaths are recorded in the national mortality register. Causes of hospital discharges or deaths were recorded according to the International classification of diseases, 8th revision (ICD-8) until 1986; thereafter, ICD-9 was used until 1995 and ICD-10 until 1998. The first three digits from the cause of admission or death were used to identify the occurrence of coronary heart disease (ICD-8 and ICD-9 codes 410-414, ICD-10 codes I21-I25).

Data on occupation at the 1980 census were obtained for $3406(82 \%)$ of the women, and level of education, recorded at the 1970 census, was obtained for 3755 (91\%) of the women through Statistics Finland. We grouped the women into three levels of education under a classification used by the Central Statistical Office: high (upper secondary and tertiary), middle (lower secondary), and low (primary). ${ }^{13}$ For 3631 (88\%) women we obtained data on taxable household income for

Abbreviations: $\mathrm{Cl}$, confidence interval; $I C D$, international classification of diseases 
the year 1980 from the national taxation register. For 3807 $(92 \%)$ of the women the occupation of the father was recorded at the child welfare clinic.

We obtained approval for the study from the ethical committee of the National Public Health Institute, Helsinki.

\section{Statistical analyses}

We examined trends in hazard ratios with neonatal and childhood measurements and socioeconomic indices by using Cox's proportional hazards model. As in previous analyses, we converted each measurement of height, weight, and body mass index for each girl to a standard deviation or z score at each birthday. ${ }^{12} \mathrm{z}$ Scores represent the difference from the mean value for the whole cohort expressed in standard deviations. We did not assign a z score at a particular age if a girl had not been measured within two years of that age.

\section{RESULTS}

Table 1 shows the characteristics of the 4130 girls at birth and at age 1 year. Seventy nine women had been admitted to hospital with coronary heart disease, of whom seven had died from the disease. A further eight had died without admission to hospital. We therefore analysed data on 87 women with coronary heart disease.

\section{Size at birth and during infancy}

Table 2 shows hazard ratios for coronary heart disease according to body size at birth. The ratios were lower in babies with higher birth weight and birth length. Though the trends were not significant, their size was similar to those in the older cohort, which included 247 women with coronary heart disease. There were no significant trends with head circumference, ponderal index (birth weight/length ${ }^{3}$ ) or length of gestation, but hazard ratios fell with increasing placental weight $(p=0.03)$. The hazard ratios were unrelated to body size at age 1 year.

\section{Childhood growth}

Figure 1 shows the growth, expressed as mean z scores, of the girls who later developed coronary heart disease. The mean $\mathrm{z}$ score for the cohort is set at zero, and a girl maintaining a steady position as large or small in relation to other girls would follow a horizontal path on the figure. Girls who later developed coronary heart disease, however, having been short at birth (table 2), grew rapidly in height up to the age of 1 year. In contrast their body mass indices fell and remained below average until the age of around 4 years, after which they began to rise progressively. Table 2 shows that the hazard ratios for coronary heart disease rose with increasing body mass index at age 11 years. We use 11 years for comparability with previous analyses but adjacent ages give similar results. After adjustment for body mass index at age
11 years, the trends in hazard ratios with birth weight and length became significant (table 2 ).

We examined the effects of increase in standard deviation score for body mass index. We used the age interval 3 to 11 years for comparability with previous analyses, but use of adjacent years gives similar results. In the past, 11 year old girls in Finland would not yet have reached menarche. ${ }^{14}$ The average age of menarche at that time was around 14 years. A one unit increase in standard deviation score for body mass index between the ages of 3 and 11 years was associated with a hazard ratio for coronary heart disease of 1.56 (95\% confidence interval (CI) 1.27 to 1.92, p $<0.001$ ). The corresponding figure for weight was 1.58 (95\% CI 1.25 to 2.01, $\mathrm{p}<0.001)$ and for height $1.18(0.88$ to $1.59, \mathrm{p}=0.28)$.

In a simultaneous regression with change in standard deviation score for body mass index between ages 3 and 11 years, the effect of body mass index at age 11 years (table 2 ) was no longer significant. We examined the combined effects of short birth length and change in body mass index score, dividing the women into two groups according to whether the standard deviation score for body mass index had decreased or increased between ages 3 and 11 years. Table 3 shows that the hazard ratio for coronary heart disease was highest among women who were $49 \mathrm{~cm}$ or less in length at birth and whose body mass index score increased.

\section{Living standards}

Hazard ratios for coronary heart disease were higher among women whose fathers were in the lower social classes, but the trend was weak and non-significant (table 4). Hazard ratios were, however, higher in women who achieved only a low level of education (table 4). Education was strongly related to father's social class. Only $10 \%$ of girls in families in which the fathers were labourers reached the highest educational level, compared with $29 \%$ of other girls. Girls who achieved only low levels of education were similar to the others in body size at birth and in rates of increase in body mass index during childhood. Women who were in the lower social classes or who had low household incomes were not at increased risk of coronary heart disease (table 4).

\section{Combined effects}

The associations between body size and growth and later coronary heart disease (tables 2 and 3) were independent of any of the four socioeconomic indices. In a simultaneous analysis coronary heart disease was associated with short length at birth, rapid increase in body mass index score between 3 and 11 years of age, and low level of education. The hazard ratios were 1.17 (95\% CI 1.03 to $1.32, \mathrm{p}=0.02$ ) for each $1 \mathrm{~cm}$ decrease in length at birth, 1.52 (95\% CI 1.23 to $1.89, \mathrm{p}<0.001)$ for each unit increase in $\mathrm{z}$ score for body mass index between ages 3 and 11 years, and 1.63 (95\% CI

Table 1 Characteristics at birth and at age 1 year of 4130 women born at Helsinki University Central Hospital during 1934-44

\begin{tabular}{llll}
\hline & Mean (SD) & Range & Number of missing values \\
\hline At birth & $3327(458)$ & $1260-5400$ & 0 \\
Birth weight $(\mathrm{g})$ & $34.8(1.4)$ & $28-41$ & 61 \\
Head circumference $(\mathrm{cm})$ & $49.9(1.8)$ & $41-59$ & 55 \\
Birth length $(\mathrm{cm})$ & $26.7(2.2)$ & $16.2-34.4$ & 55 \\
Ponderal index $\left(\mathrm{kg} / \mathrm{m}^{3}\right)$ & $640(118)$ & $230-1180$ & 9 \\
Placental weight $(\mathrm{g})$ & $280(11)$ & $251-309$ & 292 \\
Length of gestation $($ days) & $74.4(3.0)$ & $59.2-89.6$ & 7 \\
At age 1 year & $9.7(1.4)$ & $4.4-16.7$ & 7 \\
Height $(\mathrm{cm})$ & $17.4(1.6)$ & $11.9-27.1$ & 7 \\
Weight $(\mathrm{kg})$ & & & \\
Body mass index $\left(\mathrm{kg} / \mathrm{m}^{2}\right)$ & & & \\
\hline
\end{tabular}




\begin{tabular}{|c|c|c|}
\hline & Hazard ratios $(95 \% \mathrm{Cl})$ & $\begin{array}{l}\text { Number of CHD cases/ } \\
\text { number of women }\end{array}$ \\
\hline \multicolumn{3}{|l|}{ Birth weight (g) } \\
\hline$\leqslant 2500$ & $1.25(0.33$ to 4.64$)$ & $4 / 154$ \\
\hline-3000 & 1.51 (0.58 to 3.93$)$ & $26 / 803$ \\
\hline-3500 & $0.83(0.32$ to 2.13$)$ & $31 / 1771$ \\
\hline-4000 & 0.89 (0.34 to 2.37$)$ & $21 / 1146$ \\
\hline$>4000$ & 1.00 & $5 / 256$ \\
\hline$p$ for trend & 0.14 & \\
\hline $\mathrm{p}$ for trend adjusted for $\mathrm{BMI}$ at 11 years & 0.02 & \\
\hline \multicolumn{3}{|l|}{ Birth length $(\mathrm{cm})$} \\
\hline$\leqslant 48$ & $1.44(0.71$ to 2.89$)$ & $20 / 734$ \\
\hline-49 & $1.17(0.57$ to 2.41$)$ & $17 / 732$ \\
\hline-50 & $0.98(0.49$ to 1.95$)$ & $21 / 1101$ \\
\hline-51 & $1.02(0.49$ to 2.14$)$ & $15 / 781$ \\
\hline$>51$ & 1.00 & $13 / 727$ \\
\hline$p$ for trend & 0.10 & \\
\hline $\mathrm{p}$ for trend adjusted for $\mathrm{BMI}$ at 11 years & 0.01 & \\
\hline \multicolumn{3}{|l|}{ BMl at age 11 years $\left(\mathrm{kg} / \mathrm{m}^{2}\right)$} \\
\hline$\leqslant 15.9$ & 1.00 & $13 / 722$ \\
\hline-17.0 & $0.97(0.45$ to 2.10$)$ & 13/772 \\
\hline-18.4 & $1.59(0.80$ to 3.17$)$ & $21 / 766$ \\
\hline$>18.4$ & $1.79(0.89$ to 3.60$)$ & $20 / 743$ \\
\hline $\mathrm{p}$ for trend & 0.004 & \\
\hline
\end{tabular}

1.09 to $2.42, p=0.02$ ) for each decrease in level of education. No other measures of body size, growth rate, or socioeconomic status added to this regression.

\section{DISCUSSION}

We found that girls who developed coronary heart disease in later life had slow intrauterine growth that led to shortness at birth. This was followed by compensatory growth in height during infancy and rapid increase in body mass index during childhood (tables 2 and 3). Only 87 women in the cohort had developed coronary heart disease compared with 357 men in the same cohort. ${ }^{5}$ Despite this relatively small number, the associations we found were large and significant. Compared with girls who were more than $50 \mathrm{~cm}$ long at birth and whose standard deviation score for body mass index decreased between 3 and 11 years, those whose birth length was $49 \mathrm{~cm}$ or less and whose body mass index score increased had five times the risk of hospital admission or death from coronary heart disease (table 3 ). These associations between coronary heart disease and measures of body size and growth in early life were independent of indices of

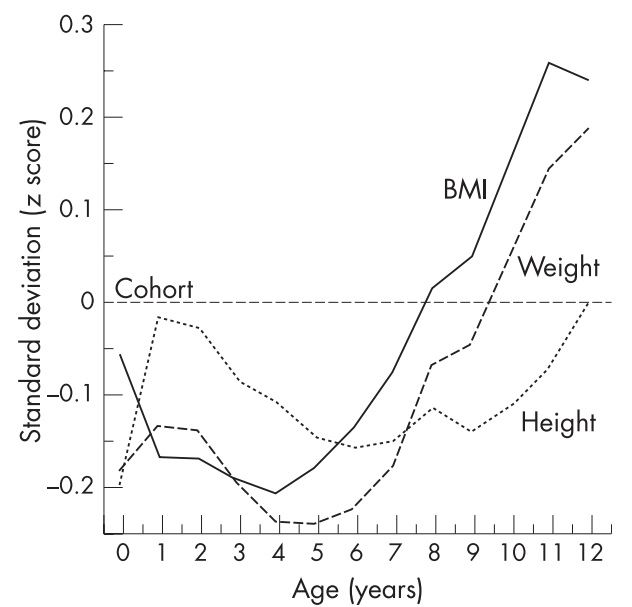

Figure 1 The growth of girls who later developed coronary heart disease. living standards in childhood and adult life. A low level of education, however, increased the disease risk independently of growth (table 4).

\section{Limitations of the study}

Of the girls we identified through birth and clinic records, $75 \%$ were still alive and resident in Finland during 1971. Our study was restricted to women who were born in Helsinki University Hospital and who attended child welfare clinics, which were voluntary. The women may therefore be unrepresentative of all women living in Helsinki, but this would introduce bias only if the associations between growth and coronary heart disease differed between those who were and those who were not included in the cohort. We have previously reported that the social class distribution of this cohort during childhood was similar to that of the city as a whole. $^{5}$ Among the children in this cohort, $63 \%$ were born into the families of labourers and $43 \%$ lived in houses with only one room. Our study data do not include information about nutrition, and associations between growth and nutrition were therefore inferred from published clinical and experimental data. ${ }^{9-11}$

\section{Comparisons with other studies}

The association between low birth weight and coronary heart disease in women has previously been shown in the UK, ${ }^{15}$ the American Nurses' Study, ${ }^{6}$ Sweden, ${ }^{3}$ and India. ${ }^{7}$ Consistent with findings in the 1924-33 Helsinki cohort, ${ }^{4}$ we found that

Table 3 Hazard ratios $(95 \% \mathrm{Cl})$ for coronary heart disease among women according to length at birth and changes in SD score for BMI between ages 3 and 11 years

\begin{tabular}{lll}
\hline & \multicolumn{2}{l}{ Change in SD score for BMI } \\
\cline { 2 - 3 } Birth length $(\mathrm{cm})$ & Decrease & Increase \\
\hline-49 & $1.72(0.56$ to 5.24$)$ & $5.08(1.92$ to 13.42$)$ \\
-50 & $1.78(0.56$ to 5.60$)$ & $4.12(1.43$ to 11.85$)$ \\
$>50$ & 1.0 & $3.46(1.23$ to 9.70$)$ \\
\hline
\end{tabular}




\begin{tabular}{|c|c|c|c|}
\hline & $\begin{array}{l}\text { Number of cases of CHD/ } \\
\text { number of women }\end{array}$ & Hazard ratio $(95 \% \mathrm{Cl})$ & $p$ for trend \\
\hline \multicolumn{4}{|c|}{ Father's social class during woman's infancy } \\
\hline Upper middle & $6 / 412$ & 1.00 & \multirow{3}{*}{0.40} \\
\hline Lower middle & $15 / 815$ & $1.20(0.47$ to 3.09$)$ & \\
\hline Labourer & $55 / 2580$ & $1.38(0.59$ to 3.21$)$ & \\
\hline \multicolumn{4}{|c|}{ Woman's level of education } \\
\hline High & $9 / 601$ & 1.00 & \multirow[t]{3}{*}{0.009} \\
\hline Middle & $18 / 1302$ & $0.99(0.45$ to 2.21$)$ & \\
\hline Low & $55 / 1852$ & 1.97 (0.97 to 3.98$)$ & \\
\hline \multicolumn{4}{|c|}{ Social class in adult life (1980 data) } \\
\hline Higher official & $17 / 771$ & 1.00 & \multirow{4}{*}{0.44} \\
\hline Lower official & $44 / 1979$ & $1.01(0.58$ to 1.76$)$ & \\
\hline Self employed & $2 / 169$ & $0.49(0.11$ to 2.14$)$ & \\
\hline Labourer & $9 / 487$ & $0.80(0.36$ to 1.79$)$ & \\
\hline \multicolumn{4}{|c|}{ Household income (1000 Finnish marks/year) (1980 data) } \\
\hline$>140$ & $18 / 709$ & 1.00 & \multirow[t]{5}{*}{0.17} \\
\hline $111-140$ & $16 / 667$ & $0.98(0.50$ to 1.92$)$ & \\
\hline $96-110$ & $3 / 453$ & $0.29(0.09$ to 0.98$)$ & \\
\hline $75-95$ & $14 / 591$ & $1.01(0.50$ to 2.03$)$ & \\
\hline$\leqslant 75$ & $32 / 1211$ & $1.15(0.65$ to 2.05$)$ & \\
\hline
\end{tabular}

short length at birth predicted coronary heart disease more strongly than low birth weight. This association is thought to reflect fetal undernutrition. ${ }^{8}$ We found that coronary heart disease was associated with small placental size, a known correlate of fetal undernutrition in humans ${ }^{16}$ Coronary heart disease was not related to small body size at age 1 year. This is consistent with findings in Hertfordshire, UK, where girls' weight at 1 year of age had no effect on disease risk. ${ }^{15}$ In the Hertfordshire study body size was not measured beyond 1 year of age.

\section{Compensatory growth}

After a period of undernutrition and reduced growth children may undergo accelerated or so called catchup or compensatory growth. ${ }^{14}$ The girls in our study who later developed coronary heart disease were short at birth. They caught up in height during infancy, but in doing so became thin. At around 4 years of age their weights and body mass indices began to increase rapidly. We suggest that this was compensatory, triggered by their thinness at that time. Several possible mechanisms exist by which reduced fetal and infant growth and accelerated weight gain in childhood may lead to coronary heart disease. Babies who are short at birth lack muscle, a deficiency that will persist, as the critical period for muscle growth is around 30 weeks in utero and there is little cell replication after birth. ${ }^{17}$ If they develop a high body mass index in childhood they may have a disproportionately high fat mass. This may be associated with the development of insulin resistance, as children and adults who had low birth weight but have become heavy are insulin resistant. ${ }^{18} 19$

\section{Comparison between the sexes}

When compared with girls from the same cohort, born to the same group of mothers, boys who later developed coronary heart disease were thin at birth, rather than short, and remained thin during infancy. ${ }^{5}$ After 1 year of age the boys who developed coronary heart disease had rapid gains in weight and body mass index. We again suggest that this was compensatory and triggered by thinness. Because they grow more rapidly in utero than girls, ${ }^{14} 2021$ boys may be more vulnerable to undernutrition at that time and respond to it differently. After birth they are generally less well able to sustain postnatal growth in adverse environments. ${ }^{14}$
Among both women and men coronary heart disease was associated with poor educational attainment and with low social class during childhood (table 4) - though in women the latter was a weak and non-significant trend. One possible explanation for the association with poor education is that it reflects general aspects of poor childhood fitness that are also related to long term health. ${ }^{22}$ Low levels of education may also be associated with less healthy behaviour in adult life. If this explained our findings, however, it is surprising that coronary heart disease among women in the cohort was not associated with poor living standards in adult life. Among women neither social class nor low household income was associated with coronary heart disease, whereas there were strong trends among men. ${ }^{13}$ These associations in men, however, were confined to those who were thin at birth.

\section{Conclusion}

Within one cohort, girls and boys who later developed coronary heart disease had similar patterns of growth. Slow fetal growth was followed by rapid weight gain in childhood. As in an older cohort of girls born in Helsinki, ${ }^{4}$ girls who later developed coronary heart disease were short at birth. They caught up in height during infancy but became thin, and began to gain weight rapidly around 4 years of age. The boys were thin at birth, remained thin during infancy, and began to gain weight rapidly around 1 year of age. In both sexes disease risk was determined by the tempo of childhood weight gain rather than by the body size attained at any particular age. Independently of growth, low educational achievement was associated with increased risk of disease.

\section{ACKNOWLEDGEMENTS}

We thank Terttu Nopanen, Tiina Saarinen, Hillevi ÖfverströmAnttila, Arja Purtonen, Tiina Valle, Hanna Pehkonen, and Ulla Tarvainen for abstracting the data from the records. Sigrid Rosten was responsible for data management. Liisa Toivanen coordinated data abstraction. The study was supported by the British Heart Foundation.

\section{Authors' affiliations}

C Osmond, D J P Barker, Southampton General Hospital, Tremona Road, Southampton, UK

T Forsén, J G Eriksson, National Public Health Institute, Helsinki, Finland 


\section{REFERENCES}

1 Barker DJP, Osmond C, Winter PD, et al. Weight in infancy and death from ischaemic heart disease. Lancet 1989;ii:577-80.

2 Frankel S, Elwood P, Sweetnam P, et al. Birthweight, body-mass index in middle age, and incident coronary heart disease. Lancet 1996;348:1478-80.

3 Leon D, Lithell HO, Vagero D, et al. Reduced fetal growth rate and increased risk of death from ischaemic heart disease: cohort study of 15000 Swedish men and women born 1915-29. BMJ 1998;317:241-5.

4 Forsen T, Eriksson JG, Tuomilehto J, et al. Growth in utero and during childhood among women who develop coronary heart disease: longitudinal study. BMJ 1999;319:1403-7.

5 Eriksson JG, Forsen T, Tuomilehto J, et al. Early growth and coronary heart disease in later life: longitudinal study. BMJ 2001;322:949-53.

6 Rich-Edwards JW, Stampfer MJ, Manson JE, et al. Birth weight and risk of cardiovascular disease in a cohort of women followed up since 1976. BMJ 1997; 315:396-400

7 Stein CE, Fall CHD, Kumaran K, et al. Fetal growth and coronary heart disease in South India. Lancet 1996;348:1269-73.

8 Barker DJP. Fetal origins of coronary heart disease. BMJ 1995;311:171-4.

9 Barker DJP, Eriksson JG, Forsén T, et al. Fetal origins of adult disease: strength of effects and biological basis. Int J Epidemiol 2002;31:1235-9.

10 Desai $M$, Hales $C N$. Role of fetal and infant growth in programming metabolism in later life. Biol Rev Camb Philos Soc 1997:72:329-48.

11 Kwong WY, Wild A, Roberts P, et al. Maternal undernutrition during the pre-implantation period of rat development causes blastocyst abnormalities and programming of postnatal hypertension. Development 2000; 127:4195-202

12 Eriksson JG, Forsen T, Tuomilehto J, et al. Catch-up growth in childhood and death from coronary heart disease: longitudinal study. BMJ 1999:318:427-31.

13 Barker DJP, Forsen T, Uutela A, et al. Size at birth and resilience to the effects of poor living conditions in adult life: longitudinal study. BMJ 2001;323:1273-6.

14 Tanner JM. Foetus into man, 2nd ed. Castlemead: Ware, 1989.

15 Osmond C, Barker DJP, Winter PD, et al. Early growth and death from cardiovascular disease in women. BMJ 1993;307:1519-24.

16 Harding JE. The nutritional basis of the fetal origins of adult disease. Int J Epidemiol 2001;30:15-23.

17 Widdowson EM, Crabb DE, Milner RDG. Cellular development of some human organs before birth. Arch Dis Child 1972;47:652-5.

18 Bavdekar A, Chittaranjan S, Fall CHD, et al. Insulin resistance syndrome in 8 -year-old Indian children: small of birth, big at 8 years or both? Diabetes 1999:48:2422-9

19 Phillips DIW. Insulin resistance as a programmed response to fetal undernutrition. Diabetologia 1996;39:1 119-22.

20 Pedersen JF. Ultrasound evidence of sexual difference in fetal size in first trimester. BMJ 1980;281:1253.

21 Garn SM, Burdi AR, Babler WJ. Male advancement in prenatal head development. Am J Phys Anthropol 1974;41:353-9.

22 Whalley LI, Deary IJ. Longitudinal cohort study of childhood IQ and survival up to age 76. BMJ 2001;322:819-22.

\section{IMAGES IN CARDIOLOGY}

\section{Extreme hypertrophic cardiomyopathy}

A 21 year old Jamaican woman with hypertrophic cardiomyopathy (HCM) was referred for sudden death risk assessment. The initial diagnosis of HCM was made at the age of 13 years and mild exertional dyspnoea has occurred since age 15 (New York Heart Association functional class II), but without syncope or chest pain. There is no family history of HCM or sudden death.

The patient's blood pressure was 104/ $60 \mathrm{~mm} \mathrm{Hg}$ and a grade 3-4/6 systolic ejection murmur was present at the apex. ECG showed diffuse $\mathrm{T}$ wave inversion, increased $\mathrm{R}$ wave voltages in V5 and V6, and deep S wave in $\mathrm{Vl}$ and $\mathrm{V} 2$.

The phenotype of HCM was striking. A two dimensional echocardiogram revealed massive and diffuse left ventricular (LV) hypertrophy; posterior free wall $=55 \mathrm{~mm}$; anterolateral free wall $=50 \mathrm{~mm}$; posterior ventricular septum $=40 \mathrm{~mm}$; and anterior ventricular septum $=32 \mathrm{~mm}$. Mitral valve systolic anterior motion was marked with prolonged septal contact. Doppler estimated a $100 \mathrm{~mm} \mathrm{Hg} \mathrm{LV} \mathrm{outflow} \mathrm{gradient} \mathrm{at} \mathrm{rest.}$ The LV end diastolic dimension was $31 \mathrm{~mm}$ and the left atrium was $42 \mathrm{~mm}$.

Based on the extreme degree of $\mathrm{LV}$ hypertrophy, a cardioverter-defibrillator was implanted prophylactically for primary prevention of sudden death. Over the subsequent two years, the device has not discharged.

This patient exhibits an extreme phenotypic expression of HCM exceeding virtually all other patients with this disease. The LV hypertrophy was massive and diffuse, involving all segments of the wall $(\geqslant 50 \mathrm{~mm}$ in two regions, $40 \mathrm{~mm}$ in one region, and predominantly involving posterior free wall), and pronounced obstruction to the LV outflow was also present under basal conditions.

B J Maron

S A Casey

A K Almquist

hcm.maron@mhif.org
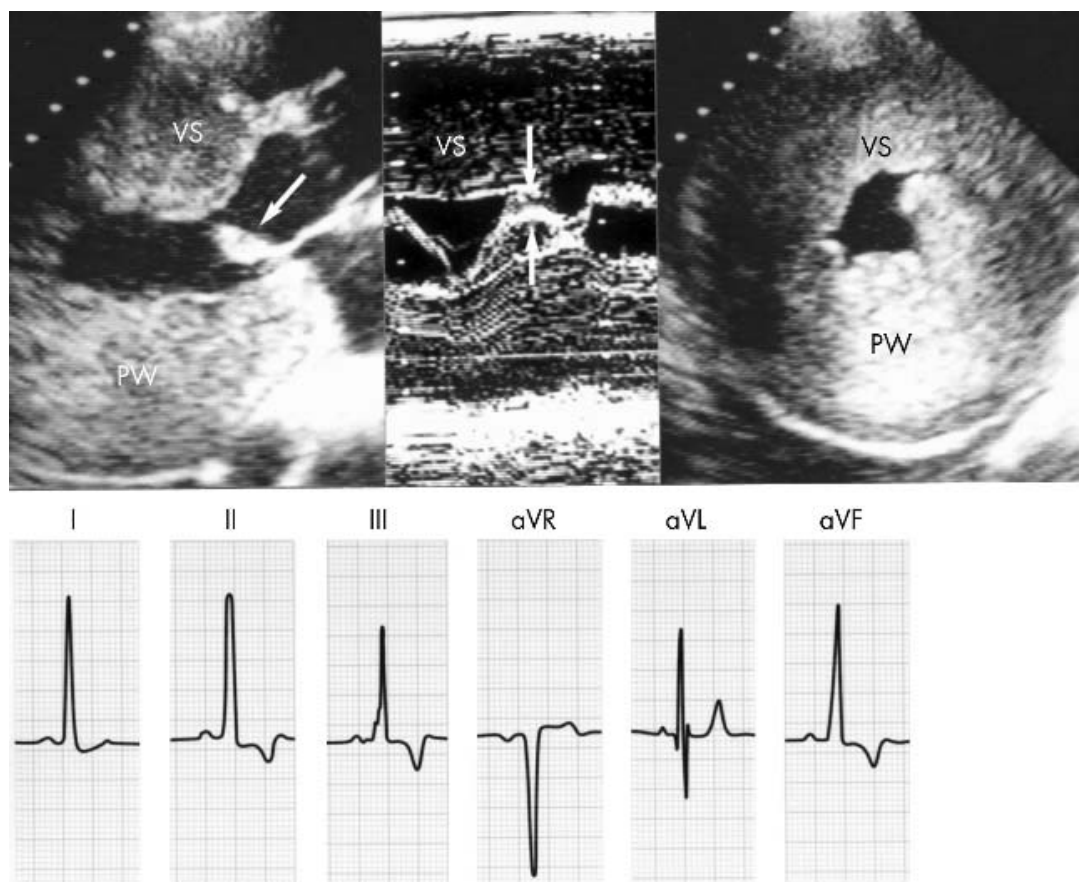

॥

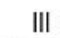

$a V R$
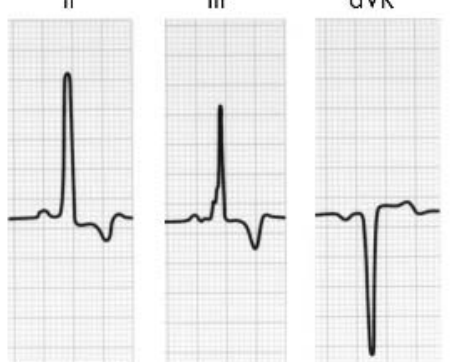

$a V L$

aVF

$V_{1}$

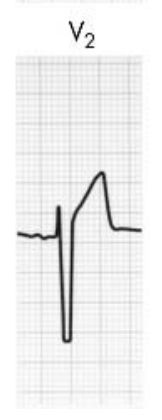

$V_{3}$

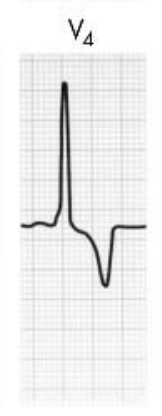

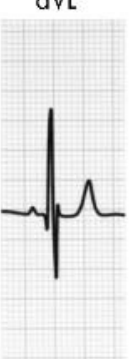
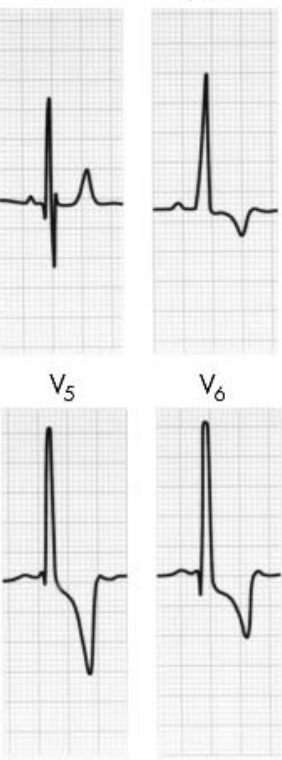

$v_{6}$

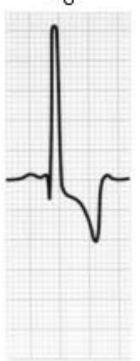

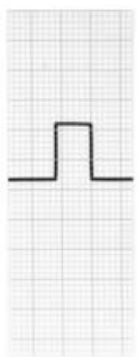

